\title{
Assessment of Essential Obstetric Care Services in Health Care Facilities in Benin City, Edo State
}

\author{
Obi $\mathrm{AI}^{1}, \mathrm{Abe} \mathrm{E}^{2}$, Okojie $\mathrm{OH}^{1,3}$ \\ ${ }^{1}$ Department of Community Health, University of Benin Teaching Hospital, PMB 1111 , Benin City, Edo State. \\ ${ }^{2}$ Department of Primary Health Care, Edo State Ministry of Health \\ ${ }^{3}$ Department of Community Health, University of Benin, PMB 1154, Benin City, Edo State
}

\begin{abstract}
Background: In Africa healthcare service delivery is a huge challenge. This is compounded by inadequate health care facilities, poor distribution and citing of health care facilities, lack of equipments and drugs to mention a few. This study was conducted to assess the level of health care facility preparedness to render basic and comprehensive essential obstetric care services to pregnant women, with view to encourage health facility deliveries and care.
\end{abstract}

Methodology: A descriptive cross sectional study design was conducted involving 114 selected Health facilities using a health facility audit tool adapted from JHPIEGO safe mother hood questionnaire. The data collected was analyzed using SPSS 16.0 statistical software with statistical significance set at $p<0.05$.

Results: One hundred and fourteen health care facilities were assessed, comprising 36(31.6\%) public and $78(68.2 \%)$ private health care facilities. Eighty eight (77.2\%) of these health care facilities were well prepared, 14(12.3\%), partially prepared and 12(10.5\%) not prepared respectively for basic essential obstetric services while $88(70.2 \%)$ well prepared, 30 (26.3\%) partially prepared and $4(3.5 \%)$ not prepared respectively to render comprehensive essential obstetric care services. Private owned health care facilities compared to public health care facilities were significantly better prepared to render both basic essential obstetric care and comprehensive obstetric care (OR=0.111; $p=0.002$ and $O R=0.082 ; p=0.01$ respectively), with availability of skilled staff identified a significant predictor for basic $(O R=0.042 ; p=0.0001)$ and comprehensive essential obstetric care $(O R=0.015 ; p=0.001)$ respectively.

Conclusion: Majority of health care facilities studied were well prepared to render essential obstetric care services but a lot more needs to be done to improve these services at the public health care facility level especially in relation to twenty four hour coverage and skilled man power needed to help improve maternal health outcome.

Key words: Assessment, Benin City, Essential Obstetric Care, Health Care Facilities, Pregnant Women

\section{Introduction}

Globally, an estimated 358000 maternal deaths occurred worldwide in 2008 and developing countries continued to account for $99 \%(355,000)$ of these deaths. ${ }^{1}$ African countries including Nigeria have failed to achieve significant reductions in maternal mortality as a result of the following: Infrastructural problems (Inadequate and inequitable distribution of Health facilities and where available basic essential obstetric care services may be lacking) coupled with logistics concerns especially in the area of supply and distribution of essential medical commodities, making referrals and receiving health care services ${ }^{2,3}$

In Nigeria, report ${ }^{4}$ shows that only $35 \%$ of births occur in health facilities, while $62 \%$ are reported to occur at home there is an increasing demand for upgrade and equipping of health facilities with the needed resources to render adequate maternal and child health services and win back the confidence of the populace especially for the public health facilities. ${ }^{4}$ In line with this, an assessment of 655 Midwives Service Scheme (MSS) PHC facilities in Nigeria revealed that $72 \%$ provided manual removal of placenta services and $70 \%$ were able to treat sepsis with available drugs while $10 \%$ did vacuum extraction and $20 \%$ manual vacuum aspiration. In addition, $84 \%$ of these facilities assessed provided aspects of newborn care. The 652 Health facilities assessed had about an average of 57\% stock of Ergometrine, oxytocin, diazepam, antibiotics, sulphadoxine pyremithamine, ferrous sulphate and folic acid. ${ }^{5}$ This may sound encouraging but not certainly a plus for a country contributing about $10 \%$ of the global average of maternal mortality. ${ }^{4}$ Furthermore, a study ${ }^{6}$ to assess Birth Preparedness and Complication Readiness in India revealed that though all health care facility studied offered 24 hours services, they lacked adequate manpower to offer emergency obstetric despite being able to offer basic obstetric care services. This study ${ }^{6}$ showed that $66.7 \%$ of these health care facilities lacked neonatal resuscitation facilities while $22.2 \%$ lacked i.v. oxytocin and by implication ill equipped to handle complication in pregnancy, delivery and post partum period. This study has again re-echoed the need for adequate manpower and basic facilities to ensure functionality of health care facilities. In a similar vein, reports from a study in Ile- 
Ife South Western Nigeria, revealed that most of the health care facilities studied did not meet the criteria to render basic and comprehensive essential obstetric care services to the populace. ${ }^{7}$ Finally, findings from another study in South Western Nigeria on the use of maternal health services revealed lack of minimal life-saving equipment at the first referral level; lack of equipment, personnel, and know-how even in referral hospitals, as major contributory factors to the high maternal mortality recorded in Nigeria. ${ }^{8}$ This study was thus conducted to ascertain health care facility readiness to render essential obstetric care services with a view to encouraging health facility delivery and care and improve maternal health outcome.

\section{Materials And Methods}

A descriptive cross sectional study was carried out in 114 health care facilities selected from Egor, Oredo and Ikpoba- Okha Local Government Areas respectively located in Benin City, the capital of Edo State. ${ }^{9}$ Benin City has a large number of public and private health institutions, some Health Institutions in Benin City include the University of Benin Teaching Hospital, Uselu Psychiatric Hospital, Central Hospital Benin, Stella Obasanjo Women and Child Hospital, Military Hospital, Airforce Base Hospital, Faith Mediplex, St Philomena Catholic Hospital among others just to mention a few. ${ }^{10}$ Minimum sample size was calculated using Cochran's formulae for descriptive study ${ }^{11}$ based on a $35 \%$ prevalence of health care facility delivery from the 2008 NDHS report ${ }^{4}$. Data collection was carried out using a health facility audit tool adapted from JHPIEGO safe mother hood questionnaire ${ }^{12}$ after obtaining a written informed consent from heads or their representatives of the selected health care facilities for study. Only health care facilities which had provided the following services at least once in the last three months preceding the study were assessed using the facility audit in the following aspects:

Basic essential obstetric care (BEOC) facilities should provide the following services:

1. Provision of twenty four hour services

2. Administer parenteral antibiotics (by intravenous drip)

3. Administer parenteral uterotonics

4. Administer parenteral anticonvulsants

5. Perform manual removal of the placenta

6. Perform removal of retained products of conception (e.g., manual vacuum aspiration)

While for health care facilities to render comprehensive essential obstetric care (CEOC) facilities it should provide all of the above services included under Basic EOC plus:

1. Perform surgery (e.g., cesarean section)

2. Provide anesthesia

3. Perform blood transfusion

The level of preparedness for essential obstetric care was graded based on the following; point score of one was allocated to each aspect of essential obstetric care above making a total of six (6) points score for basic essential obstetric care and three (3) additional point score for comprehensive emergency obstetric care. Having a score of $\geq 4$ points for basic essential obstetric care and additional $\geq 2$ points for comprehensive essential obstetric care, thus giving a grand score of $\geq 6$ points ( $i . e \geq 4$ and or $\geq 2$ points respectively) the facility was considered as being well prepared, while having $1-2$ points score for basic essential obstetric and or additional 1 point for comprehensive essential obstetric care giving a grand total of $\leq 3$ points (i.e $1-2$ points and or 1 point respectively) the health care facility was considered as being partially prepared. Finally having a score of zero (0) point for either basic or comprehensive essential obstetric care the health care facility was considered as not prepared. The data collected was analyzed using SPSS 16.0 statistical software with statistical significance set at $\mathrm{p}<0.05$.

\section{Results}

A total of $78(68.3 \%)$ private health care facilities and $36(31.6 \%)$ public health care facilities were assessed in this study. In relation to the facilities available for BPACR in the health facilities studied, Table 1 shows that all the health care facilities (public and private) studied had client waiting room while a higher proportion of private health care facilities $77(98.7 \%$ ) and $77(98.7 \%)$ had water and light source compared to $32(88.9 \%)$ and $34(94.4 \%)$ respectively for public health facilities. In relation to basic drugs for obstetric care $78(100.0 \%)$ private health care facilities than $34(94.4 \%)$ public health facilities had intravenous antibiotics, similarly a higher proportion of private $78(100.0 \%)$ had intravenous uterotonic (oxytocin) than public health care facilities 33(91.7\%), in contrast a slightly higher proportion of public health care facilities $34(94.4 \%)$ compared to private health care facilities $73(93.6 \%)$ had intravenous anxiolytics. Furthermore, a higher proportion of private $68(87.2 \%)$ than public health care facilities $12(33.3 \%)$ had Karman syringe for manual vacuum aspiration of retained products of conception. Finally, a higher proportion of private health care facilities $67(85.9 \%)$ have operating room compared to public health care facilities $9(25.0 \%)$. 
In relation to services rendered by health care facilities studied Table 2 shows that a higher proportion 76 (97.4\%) of private health care facilities rendered twenty four hour services compared to $13(36.1 \%)$ public health care facilities. Also, a higher proportion $7(19.4 \%)$ of public health facilities have active health committee compared to $2(2.6 \%)$ for private health care facilities. In addition, all the health care facilities studied have trained staff for manual removal of placenta. Furthermore, a higher proportion 55(70.5\%) of private health care facilities studied were involved in blood transfusion in the past three months compared to $8(22.2 \%)$ of public health care facilities. In relation to laboratory services available a higher proportion $28(77.8 \%)$ of public health care facilities than $15(19.2 \%)$ for private health care facilities have onsite laboratory compared to a higher proportion $63(80.8 \%$ ) of private health care facilities than public health care facilities $8(22.2 \%)$ that had off-site laboratory respectively. In relation to caesarian section, a higher proportion $56(71.8 \%)$ of private health care facilities than $8(22.8 \%)$ for public health care facilities performed caesarian section in the past three months, in addition a higher proportion $66(84.6 \%)$ of private health care facilities than $21(58.3 \%)$ public health facilities provide anaesthesia. Finally, a higher proportion $67(85.9 \%)$ of private health care facilities than $9(25.0 \%)$ public health care facilities had staff available for operation.

In relation to heath care facility level of preparedness for Basic and Comprehensive Essential Obstetric Care, Figure 1 shows that majority of the health care facilities $80(70.2 \%)$ studied were well prepared for comprehensive essential obstetric care but slightly less when compared to $88(77.2 \%)$ for basic essential obstetric care. Thirty $(26.3 \%)$ health care facilities were partially prepared for comprehensive essential obstetric care as compared for basic essential obstetric care 14(12.3\%). Finally, 4(3.5\%) of the health care facilities studied were not prepared to render comprehensive essential obstetric care services and this was less when compared to $12(10.5 \%)$ for basic essential obstetric care.

In relation to factors associated with level of preparedness of health care facilities for basic Essential Obstetric Care Table 3 shows that majority of private health care facilities $75(96.2 \%)$ than public health care facilities $13(36.1 \%)$ were more prepared to render basic essential obstetric care and the difference was statistically significant $(\mathrm{p}<0.01)$. Furthermore, Health care facilities with water source available $87(79.8 \%)$ than those without $1(20.0 \%)$ were significantly $(\mathrm{p}<0.01)$ better prepared to offer basic essential obstetric care. Health care facilities with available staff $74(77.4 \%)$ than those without available staff $14(36.8 \%)$ were statistically better prepared to render basic essential obstetric care $(p<0.01)$

In relation to factors associated with level of preparedness of health care facilities for comprehensive Essential Obstetric Care Table 4 shows that Majority $71(91.0 \%)$ of private than public health facilities $9(25.0 \%)$ were better well prepared to render comprehensive essential obstetric care and this difference was statistically significant $(p<0.01)$. In addition, health care facilities with water source $79(72.5 \%)$ available were significantly $(\mathrm{p}=0.01)$ better prepared to render comprehensive essential obstetric care services than those that did not have 1(20.0\%). Finally, in relation to the availability of operating room, health facilities with operating room $77(93.9 \%)$, with staff available $74(97.4 \%)$ were better prepared to render comprehensive essential obstetric care than those without operating room $3(9.4 \%)$ and staff $6(15.8 \%)$ these differences were statistically significant $(\mathrm{p}<0.01$ respectively).

Furthermore, in relation to result of Logistic Regression model for predictors of level of preparedness of Health Care Facilities for Basic Essential Obstetric Care Table 5 shows that availability of water source was not identified as a significant predictor for level of preparedness of health facilities for basic essential obstetric care while category of health facility was a significant predictor identified $(\mathrm{OR}=0.11 ; p<0.01)$ for level of preparedness of health facilities for basic essential obstetric care, as the odds of being well prepared for basic essential obstetric care in the public health facilities was 9 times less than in private health facilities. Finally, in relation to availability of staff, the odds of being well prepared for basic essential obstetric care was 25 times more in facilities with available staff than those without available staff $(\mathrm{OR}=0.04 ; \mathrm{p}<0.01)$. Availability of water source and availability of operating room were not identified as significant predictors of level of preparedness for comprehensive essential obstetric care.

In relation to result of Logistic Regression model for predictors of level of preparedness of Health Care Facilities for comprehensive Essential Obstetric Care Table 6 shows that the category of health facility was a significant predictor for comprehensive essential obstetric services $(\mathrm{OR}=0.08 ; p=0.01)$ as the odds of being well prepared for comprehensive essential obstetric care services by pubic health care facilities was 12.5 times less than in private health facilities. Finally, availability of staff for operation was also a significant predictor for level of preparedness for comprehensive essential obstetric care $(\mathrm{OR}=0.02 ; p<0.01)$ as the odds of being well prepared for comprehensive essential obstetric care in health facilities with available staff was 50 times less than in facilities without available staff for twenty four hours.

\section{Discussion}

Majority of the health care facilities studied were well prepared to render both basic and comprehensive essential obstetric care. The category of health care facility and availability of staff were 
identified as significant predictors of level of preparedness for essential obstetric care in this study. Furthermore, private health care facilities were better well prepared to render essential obstetric care than public health facilities. It was also, identified in this study that private health care facilities were better equipped in terms of facilities, equipments, manpower and services than the public health facilities, this may have possibly influenced the level of preparedness of the public health care facilities to render essential obstetric care when compared to the private health facilities. The private sector is also possibly more profit-oriented and experience less hitches in decision making as relates to provision of needed resources to enhance their performance in service delivery than public health care facilities.

These findings are in contrast to reports of a study in Ile-Ife South Western Nigeria, where most of health facilities studied did not meet the criteria to render basic and comprehensive essential obstetric care services to the populace. ${ }^{7}$ Another study in India which assessed health facility readiness for obstetric care, revealed that though the facilities studied offered 24 hours services they lacked adequate man power, drugs and equipment to offer comprehensive obstetric care and newborn care, though they all rendered basic obstetric care services. ${ }^{6}$ The health care system in developing countries is characterized by misplaced priorities, inaccessibility of essential health information to the women most affected, physical as well as socio-economic and geographical barriers separating health services from most women and delays in seeking and receiving adequate and appropriate care often exist. ${ }^{13}$ Others factors also reported include, lack of minimal life-saving equipment at the first referral level; the lack of equipment, personnel, and know-how even in referral hospitals, as key factors that can influence health care delivery. ${ }^{13}$

These problems with the health system especially with the public sector (public health facilities) have strong ties with poor political will and poor attitude to work by Government and the health care providers as reported in previous studies ${ }^{14-16}$. This can influence the level of utilization of care in favour of private facility care, especially when this becomes "news'. The financial implication of seeking care outside public health care facilities may necessitate the utilization of unskilled care from quacks and TBAs, due to higher cost of care in private settings. If these problems remain unchecked, it can greatly influence efforts to achieve considerable reduction in maternal morbidity through the utilization of unskilled care.

The findings from this study in relation to level of preparedness of public health care facilities for essential obstetric care are in contrast to that reported in the assessment of Midwives Service Scheme PHC (Public) facilities in Nigeria ${ }^{5}$ which showed that majority of MSS PHC facilities studied rendered basic essential obstetric care and new born care and were well equipped with drugs and equipment to do so. It is noteworthy to mention that the inadequate supplies of essential drugs, such as antibiotics, oxytocics, and anti-convulsants, observed especially in public health facilities at the Local Government level, are avoidable factors that contribute and compound delays ${ }^{4}$ in receiving care and the associated maternal morbidity and mortality that could arise due to poorly equipped health care facilities. This problem of lack of necessary equipment to render the intended health care services to the populace especially during life threatening situation have also been linked to maternal mortality. ${ }^{17}$

Finally, a study ${ }^{8}$ in Ile-Ife, South Western Nigeria on the determinants for use of maternal health services in Nigeria revealed that lack of minimal life-saving equipment at the first referral level, the lack of equipment, personnel, and know-how even in referral hospitals are significant factors influencing the maternal health services. ${ }^{8}$ The health system in Nigeria and especially in developing countries need to exercise caution and ensure that its maternal and child health interventions as encapsulated in the Midwives Service Scheme goes beyond paper work to ensuring proper implementation and regular programme evaluation for improved performance in our maternal and child health indices.

\section{Conclusion}

Majority of health care facilities studied were well prepared to render essential obstetric care services with category of health care facility and availability of staff identified as significant predictors for this outcome. Private health care facilities were identified to be better well prepared to render both basic and comprehensive essential obstetric care services than their public health care facilities counterparts. Health care facilities should be adequately equipped especially at the public health care level to render better health care services to the populace and improve maternal health outcome.

\section{Limitation of Study}

This study was based on self report as it may be difficult validating claims made by respondents.

\section{Acknowedgement}

We wish to in a very special way thank the Management of the University of Benin Teaching Hospital, Project Supervisor (Professor Obehi .H. Okojie), Research assistants, Heads and representatives of the health care facilities studied for their support in ensuring the success of this research work 


\section{Competing Interest}

We wish to state in very clear terms that this study was conducted free of any competing interest.

\section{References}

[1]. WHO, UNICEF, UNFPA and World Bank. Trends in Maternal Mortality: 1990 to 2008: Estimates developed by WHO, UNICEF, UNFPA and The World Bank. Geneva, WHO, 2010.

[2]. World Health Organization (WHO). Partnership for Maternal, Newborn and Child health Resources. Study of maternal and neonatal morbidity in Africa in Rural Integrated Relief Service - Ghana ; 2007

[3]. Kimani M. Investing in the Health of Africa's Mothers. Afr Renewal 2008;21(4);8

[4]. National Population Commission (NPC). Federal Republic of Nigeria and ORC Macro, Nigeria Demographic and Health Survey 2008, Calverton, MD, USA: NPC and ORC Macro. 2010.

[5]. National Primary Health Care Development Agency. The MGD -DRG Funded Midwives services Scheme, Concept, processs and progress. Abuja, 2010

[6]. Nandan D,Kushwah SS, Dubey DK. A study for assessing Birth Preparedness and Complication Readiness Intervention in Rewa District of Madhya Pradesh, India.2008 p 1-34.

[7]. Ijadunola KT, Fatusi AO, Orji EO, Adeyemi AB, Owolabi OO, Ojofeitimi EO,Omideji AK, Ademuyi AA: Unavailability of essential obstetric care services in a Local Government Area in South West Nigeria. J Health Popul Nutri. 2007 March; 25(1):94100

[8]. Babalola S, Fatusi A. Determinants of use of maternal health services in Nigeria--looking beyond individual and household factors. BMC Pregnancy Childbirth. 2009;9: 43.

[9]. Eni-Meg Nigeria Limited. Edo State Investors' Guide ( $1^{\text {st }}$ Edition International). Eni-Meg. Publishers, Lagos, $1999: 2-256$

[10]. Edo State Ministry of Health. Department of Hospital services, List of Health Facilities.

[11]. Cochran WG. Sampling techniques (3rd ed.).1977.New York: John Wiley \& Sons

[12]. JHPIEGO. Maternal and neonatal health. Monitoring birth preparedness and complication readiness, tools and indicators for maternal and newborn health. Johns Hopkins, Bloomberg school of Public Health, Center for communication programs, Family Care International; 2004.

[13]. Sundari TK. The untold story: how the health care systems in developing countries contribute to maternal mortality. International Journal Health Service. 1992;22(3):513-528. doi: 10.2190/91YH-A52T-AFBB-1LEA. [Cross Ref]

[14]. Onah HE, Ikeako LC, Iloabachie GC: Factors associated with the use of maternity services in Enugu, South Eastern Nigeria. Soc Sci Med 2006, 63: 1870 - 78. PubMed Abstract

[15]. Kyomuhendo GB: Low use of maternity services in Uganda: Impact on women's status, traditional beliefs and limited resources. Reprod Health Matters 2003, 11(21): 16-26. PubMed Abstract| Publisher Full Text

[16]. Asuquo EEJ, Etuk SJ, Duke F: Staff attitude as barrier to the utilization of University of Calabar Teaching Hospital for Obstetric care. African Journal of Reproductive Health 2000, 4(2):69-73. Publisher Full Text

[17]. Igberase GO, Isah EC, Igbekoyi OF. Awareness and perception of maternal mortality among women in a semi-urban community in the Niger Delta of Nigeria. Ann Afr Med 2009, 8(4); 261- 65

Appendix

Table 1: Facilities available for BPACR in Health Care Facilities in Benin City

\begin{tabular}{|c|c|c|}
\hline Variable & $\begin{array}{c}\text { Public Health Facilities Frequency } \\
\qquad \begin{array}{c}(\%) \\
\mathbf{n}=36\end{array}\end{array}$ & $\begin{array}{c}\text { Private Health Facilities Frequency } \\
\qquad \begin{array}{c}(\%) \\
n=78\end{array}\end{array}$ \\
\hline \multicolumn{3}{|c|}{ Have A Client Waiting Area } \\
\hline Yes & $36(100.0)$ & $78(100.0)$ \\
\hline \multicolumn{3}{|c|}{ Water Source } \\
\hline Yes & $32(88.9)$ & $77(98.7)$ \\
\hline No & $4(11.1)$ & $1(1.3)$ \\
\hline \multicolumn{3}{|c|}{ Light Source } \\
\hline Yes & $34(94.4)$ & $77(98.7)$ \\
\hline No & $2(5.6)$ & $1(1.3)$ \\
\hline \multicolumn{3}{|c|}{ Intravenous Antibiotics } \\
\hline Yes & $34(94.4)$ & $78(100.0)$ \\
\hline No & $2(5.6)$ & $0(0.0)$ \\
\hline \multicolumn{3}{|c|}{ Karman Syringe } \\
\hline Yes & $12(33.3)$ & $68(87.2)$ \\
\hline No & $24(66.7)$ & $10(12.8)$ \\
\hline \multicolumn{3}{|c|}{ Oxytocin (IV Uterotonic) } \\
\hline Yes & $33(91.7)$ & $78(100.0)$ \\
\hline No & $3(8.3)$ & $0(0.0)$ \\
\hline \multicolumn{3}{|c|}{ I.V Anxiolytic } \\
\hline Yes & $34(94.4)$ & $73(93.6)$ \\
\hline No & $2(5.6)$ & $5(6.4)$ \\
\hline \multicolumn{3}{|c|}{ Have Operating Room } \\
\hline Yes & $10(27.8)$ & $72(92.3)$ \\
\hline No & $26(72.2)$ & $6(7.7)$ \\
\hline
\end{tabular}


Table 2: Services provided for BPACR in Health Care Facilities in Benin City

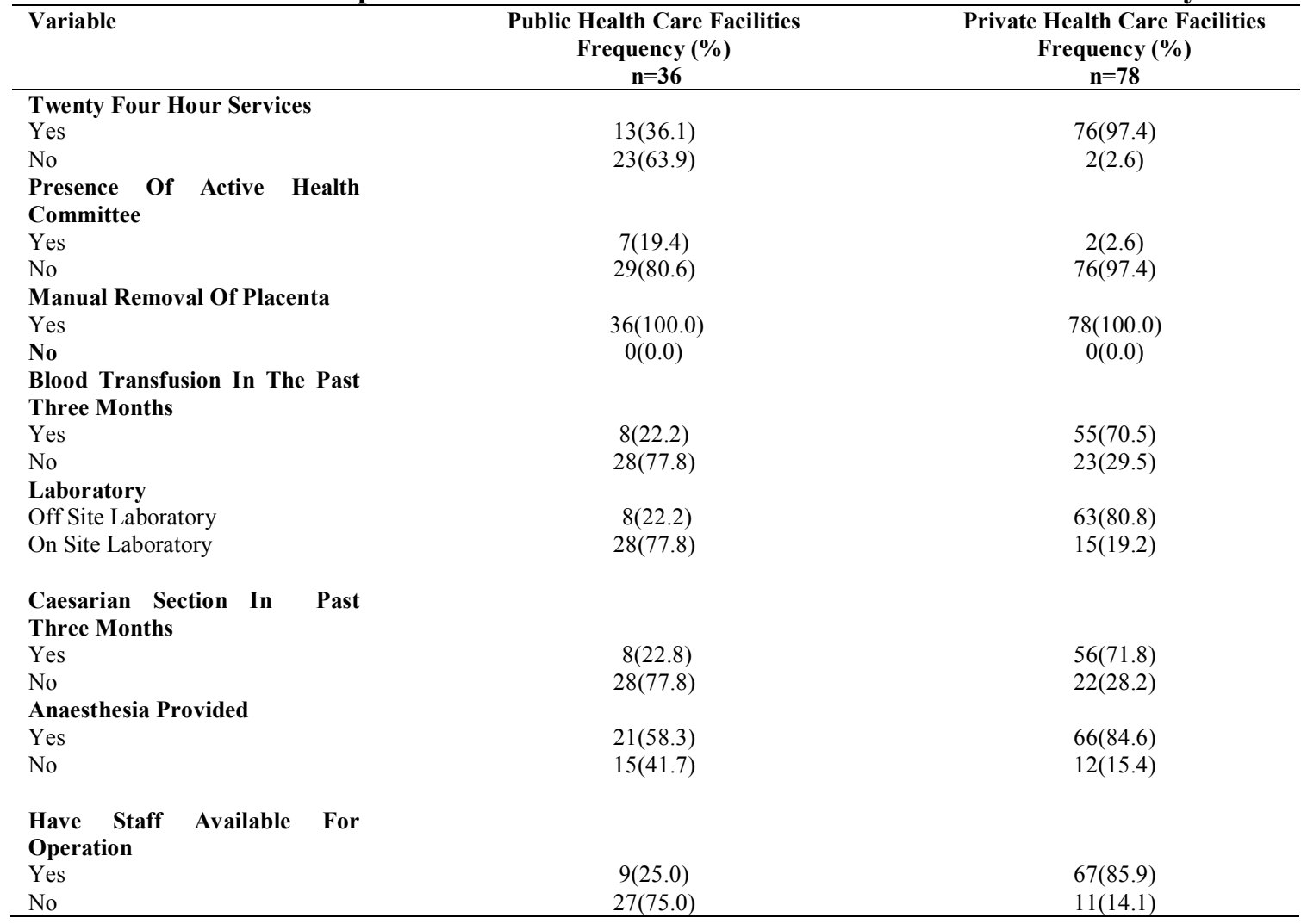

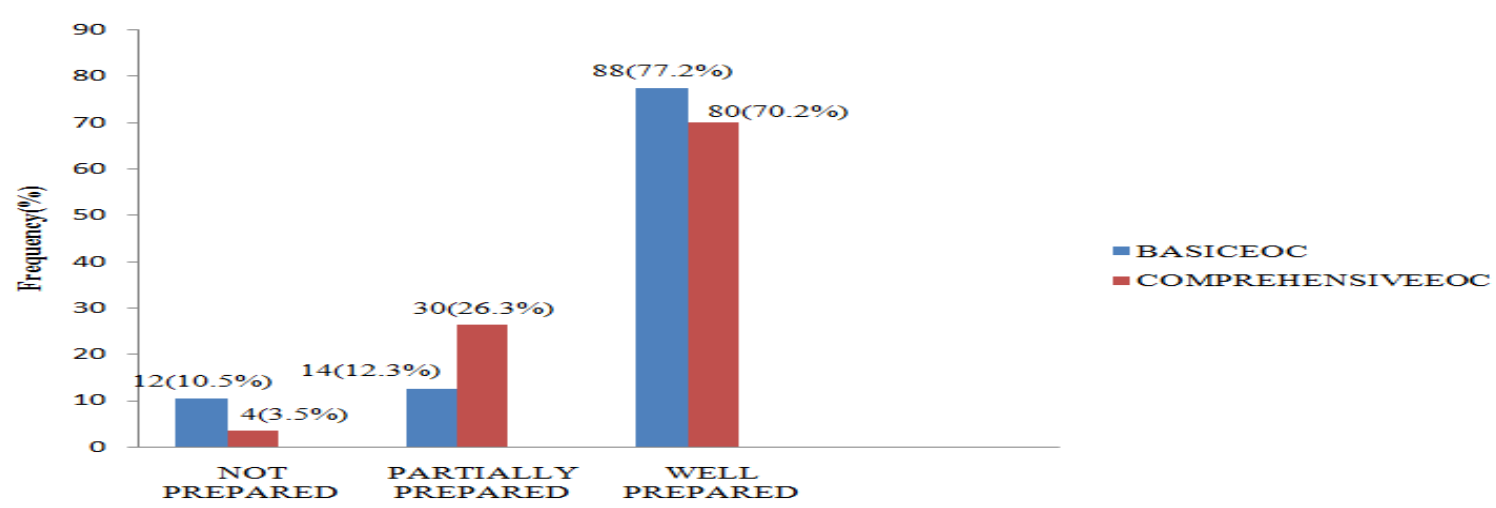

Figure 1: Heath Care Facility Level of Preparedness for Basic and Comprehensive Essential Obstetric Care

Table 3: Factors Associated with Level of Preparedness of Health Care Facilities for Basic Essential Obstetric Care

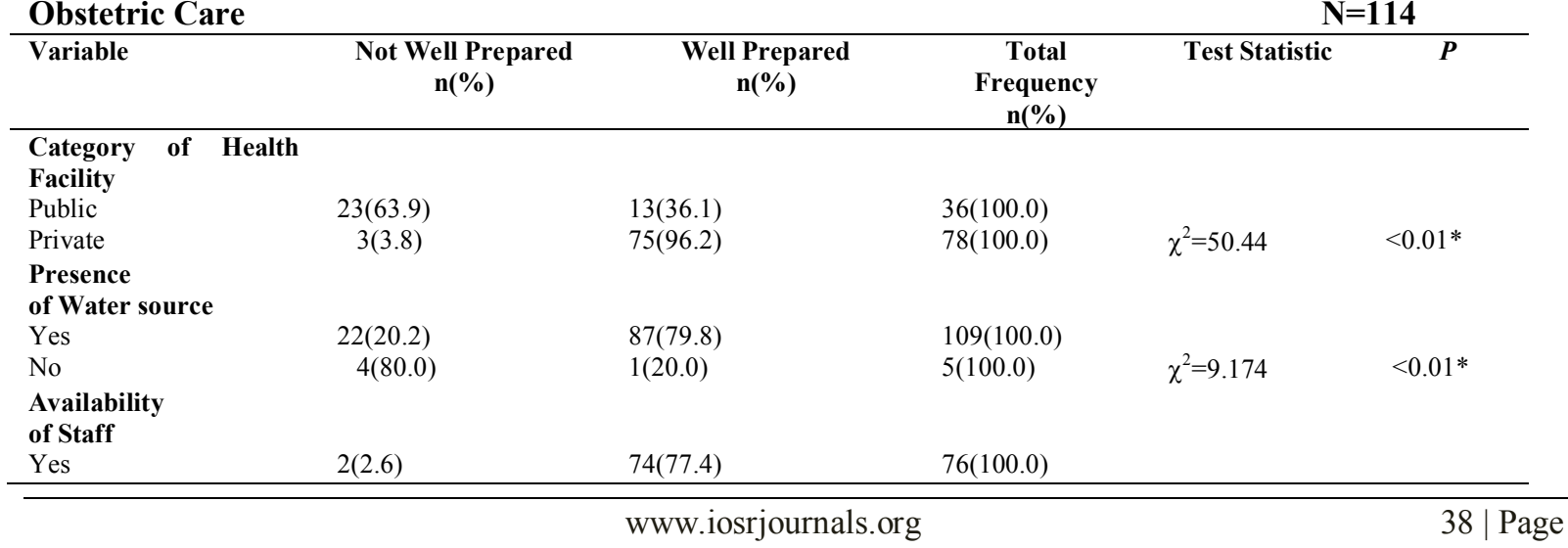


Assessment of Essential Obstetric Care Services in Health Care Facilities in Benin City, Edo State

\begin{tabular}{|c|c|c|c|c|c|}
\hline No & $(63.2)$ & $14(36.8)$ & $\chi^{2}=52.71$ & $<0.01 *$ & \\
\hline \multicolumn{6}{|c|}{ *Significance at $\mathbf{p}<0.05$} \\
\hline \multicolumn{6}{|c|}{ Table 4: Factors Associated with Level of Preparedness of Health Care Facilities for Comprehensive } \\
\hline \multicolumn{2}{|c|}{ Essential Obstetric Care Services } & & & \multicolumn{2}{|c|}{$\mathrm{N}=114$} \\
\hline Variable & $\begin{array}{l}\text { Not Well Prepared } \\
\text { n(\%) }\end{array}$ & $\begin{array}{c}\text { Well Prepared } \\
\text { n(\%) }\end{array}$ & $\begin{array}{c}\text { Total } \\
\text { Frequency n(\%) }\end{array}$ & Test Statistic & p value \\
\hline \multicolumn{6}{|c|}{ Category of Health Facility } \\
\hline Public & $27(75.0)$ & $9(25.0)$ & $36(100.0)$ & & \\
\hline Private & $7(9.0)$ & $71(91.0)$ & $78(100.0)$ & $\chi^{2}=51.31$ & $<0.01 *$ \\
\hline \multicolumn{6}{|c|}{ Presence of Water Source } \\
\hline Yes & $30(27.5)$ & $79(72.5)$ & $109(100.0)$ & & \\
\hline No & $4(80.0)$ & $1(20.0)$ & $5(100.0)$ & $\chi^{2}=6.29$ & $0.01 *$ \\
\hline \multicolumn{6}{|c|}{$\begin{array}{l}\text { Availability } \\
\text { of Operating Room }\end{array}$} \\
\hline Yes & $5(6.1)$ & $77(93.9)$ & $82(100.0)$ & & \\
\hline No & $29(90.6)$ & $3(9.4)$ & $32(100.0)$ & $\chi^{2}=78.58$ & $<0.01 *$ \\
\hline \multicolumn{6}{|c|}{ Availability of Staff } \\
\hline Yes & $2(2.6)$ & $74(97.4)$ & $76(100.0)$ & & \\
\hline No & $32(84.2)$ & $6(15.8)$ & $38(100.0)$ & $\chi^{2}=80.55$ & $<0.01 *$ \\
\hline
\end{tabular}

*significance at $\mathbf{p}<0.05$

Table 5: Result of Logistic Regression model for predictors of level of preparedness of Health Care Facilities for Basic Essential Obstetric Care

\begin{tabular}{lccc}
\hline Variable & Odds Ratio & $\mathbf{9 5 \%}$ Confidence Interval & $p$ \\
\hline $\begin{array}{l}\text { Category of Health facility } \\
\text { Public }\end{array}$ & 0.111 & $0.027-0.455$ & $<0.01 *$ \\
$\begin{array}{l}\text { Private } \\
\text { Presence of water source }\end{array}$ & 1.000 & & 0.41 \\
No & 0.489 & $0.032-5.193$ & $<0.01 *$ \\
Yes & 1.000 & & \\
$\quad$ Availability of staff & & & \\
No & 0.407 & $0.032-5.193$ & \\
Yes & 1.000 & &
\end{tabular}

*significance at $\mathbf{p}<0.05$

Table 6: Result of Logistic Regression Model for Predictors of Level of Preparedness of Health Care Facilities for Comprehensive Essential Obstetric Care

\begin{tabular}{lcc}
\hline Variable & Odds Ratio & $\mathbf{9 5 \%}$ Confidence interval \\
\hline Category of Health facility & 0.08 & $0.01-0.55$ \\
Public & 1.00 & \\
Private & 2.04 & $0.09-46.63$ \\
Presence of water source & 1.00 & \\
No & & \\
Yes & 0.02 & $0.00-0.19$ \\
Availability of Staff & 1.00 & \\
No & & \\
Yes & 0.38 & $0.04-3.77$ \\
Availability of operating room & 1.00 & \\
No & & \\
Yes & & \\
\hline
\end{tabular}

*Significance at $\mathrm{p}<0.05$ 